Revue d'histoire de l'Amérique française

REYUE D.HISTOIRE DE L'AMÉRIQUE FRANÇAISE

\title{
Correspondance de sir Joseph Dubuc
}

\section{Eugénie Dubuc}

Volume 20, numéro 2, septembre 1966

URI : https://id.erudit.org/iderudit/302571ar

DOI : https://doi.org/10.7202/302571ar

Aller au sommaire du numéro

Éditeur(s)

Institut d'histoire de l'Amérique française

ISSN

0035-2357 (imprimé)

1492-1383 (numérique)

Découvrir la revue

Citer ce document

Dubuc, E. (1966). Correspondance de sir Joseph Dubuc. Revue d'histoire de l'Amérique française, 20(2), 291-292. https://doi.org/10.7202/302571ar d'utilisation que vous pouvez consulter en ligne.

https://apropos.erudit.org/fr/usagers/politique-dutilisation/ 


\section{DOCUMENTS INÉDITS}

\section{CORRESPONDANCE DE SIR JOSEPH DUBUC}

Nous commencerons, en décembre prochain, la publication de la correspondance de Joseph Dubuc. Dubuc partait pour l'Ouest au printemps de 1870. Il répondait à un appel pressant de son ami Louis Riel (chef du gouvernement provisoire), camarade de collège, qui désirait avoir près de soi un homme de loi. Aussitôt arrivé, il envoyait à la Minerve de Montréal, une série de lettres où il racontait les événements qui se déroulaient là-bas. On comprendra l'importance d'une telle correspondance. Elle servit grandement à éclairer l'opinion dans le Québec. Joseph Dubuc, alors jeune avocat, choisit de rester au Manitoba. Il devait devenir plus tard sir Joseph Dubuc.

Nous publions, aujourd'hui, en tête de cette correspondance, une courte biographie du personnage que nous devons à l'une de ses très proches parentes, sa nièce, Mlle Eugénie Dubuc, aujourd'hui présidente de la Société historique de Saint-Boniface, Manitoba. En décembre, paraîtra aussi un "Extrait de l'autobiographie de Sir Joseph Dubuc".

\section{PETITE BIOGRAPHIE DE SIR JOSEPH DUBUC}

Joseph Dubuc, fils de Joseph Dubuc et Euphémie Garand, est né à Ste-Martine, comté de Châteauguay, le 26 décembre 1840. Il fut l'aîné de 15 enfants. En 1847, la famille déménageait à St-Rémi, Napierville, et c'est dans cette paroisse, à deux milles et demi du village qu'il commença ses études primaires. L'école était bâtie sur la terre de son père. A l'âge de 13 et 14 ans, il ne fréquente l'école que pendant la saison d'hiver, pour aider son père dans les travaux de la ferme, il cessa alors de fréquenter l'école.

Mais il désirait ardemment faire un cours classique et priait constamment le ciel pour obtenir cette faveur. Il fut exaucé. 
En septembre 1859, il entre comme interne au Collège des Frères des Écoles Chrétiennes de Beauharnois. Pour le logement et l'instruction, ça ne coûtait qu'une piastre par mois. Mais la famille fournissait le pain, la viande, le beurre et les pois pour la soupe. Ce collège donnait un cours commercial, mais pour Joseph Dubuc c'était un commencement et il sentait irrésistiblement que de là il irait plus loin. Aimant l'étude, désirant vivement s'instruire et ayant du talent, toute l'année à Beauharnois il fut premier de classe. Le curé, Messire Charland, le remarqua, le fit mander au presbytère et lui dit: "Je vais parler à ton curé, le Révérend Monsieur Bédard, pour qu'il te mette au Collège." Monsieur Bédard fut donc son grand protecteur. Joseph Dubuc entre au Collège de Montréal en septembre 1860. Il fait le cours classique de 8 ans en 6 ans.

Après son baccalauréat, il s'inscrit à l'Université McGill pour ses études de droit, se présente à l'examen pour l'admission de la pratique le 10 juillet 1869 , et reçoit son diplôme d'avocat le 1 er septembre 1869 , se classant premier.

Il ouvre alors un bureau avec un de ses amis, Henry Wight, avocat depuis environ un an et condisciple du Collège de Montréal. C'est à ce bureau qu'il reçoit les lettres de Riel et se décide à partir pour le Manitoba en mai 1870.

Sir Joseph Dubuc fut membre de la première Législature du Manitoba, surintendant d'Éducation, président de l'Assemblée législative et procureur général de la province, membre et aviseurlégal $\mathrm{du}$ Conseil $\mathrm{du}$ Nord-Ouest, député aux Communes du Canada pour le comté de Provencher, juge de la Cour du Banc du Roi, juge en Chef et administrateur de la Province, vicechancelier de l'Université, chevalier de l'Ordre de St-Michel et St-Georges.

À St-Rémi, sur la terre paternelle, la paroisse a érigé un monument en son honneur.

EUGÉNIE DUBUC, présidente de la Société historique de Saint-Boniface, Manitoba. 